\title{
Methylated septin 9 gene is an important prognostic marker in stage II and stage III colorectal cancer for evaluating local recurrence or distant metastasis after surgery
}

Mingliang Huang ${ }^{1 \dagger}$, Jiehua He ${ }^{3,4+}$, Wei Lai ${ }^{1 \dagger}$, Lu Liu' ${ }^{1}$, Heyang Xu' ${ }^{1}$ Yujie Zeng ${ }^{1}$, Qiusheng Lan ${ }^{1}$, Xiangan Lin ${ }^{2^{*}}$ and Zhonghua $\mathrm{Chu}^{1 *}$

\begin{abstract}
Background: Abnormal hypermethylation of the septin 9 gene was an inchoate incident in some cancers. Though latest several researches had paid attention to its value in prognosis, the consequences were not distinctly, especially in colorectal cancer (CRC) with stage II and stage III.

Purpose: The aim of this research was to pick up the prognostic value of the methylated septin 9 gene (mSEPT9) in CRC patients, particularly in TNM stage II-III.

Methods: Blood samples before surgery were obtained from 144 CRC patients, of which there were 94 with stage II and stage III. mSEPT9 was considered positive when the cycle number of the peak reaction (Ct) was lower than the threshold value (41.0) for two times during three times PCR test. MSEPT9 and other relative factors of prognosis were estimated by survival analysis. The level of septin 9 in tissues was tested by immunohistochemical (IHC).

Results: Stage II and stage III patients with mSEPT9 positive (mSEPT9+) had a lower disease-free survival (DFS) rate than those with mSEPT9 negative (mSEPT9-) (2-year DFS rates, $52.1 \%$ vs $73.9 \%, P=0.014)$. In multivariate regression analysis, $\mathrm{mSEPT} 9$ was also an independent predictor of prognosis $(H R=2.741, P=0.009)$. The risk of local recurrence or distant metastasis in CRC patients after surgery was mSEPT9+ with stage III, mSEPT9- with stage III/mSEPT9+ with stage $I$, and mSEPT9- with stage II $(P=0.001)$, from highest to lowest. In addition, mSEPT9 was strongly associated with TNM staging, tumor immersion depth, distant metastasis, differentiation degree, vascular invasion and microsatellite. When we explored the associations between septin 9 protein level revealed by $\mathrm{IHC}$ and other elements, recurrence/progression $(R=-0.523, P=0.001)$, mSEPT9 status $(R=-0.451, P=0.004)$ and T stage $(R=-0.375, P=0.017)$ showed significant correlations.
\end{abstract}

\footnotetext{
*Correspondence: Ixg1005@126.com; sumschuzhonghua@hotmail.com ${ }^{\dagger}$ Mingliang Huang, Jiehua He and Wei Lai have the same contribution to this work.

${ }^{1}$ Guangdong Provincial Key Laboratory of Malignant Tumor Epigenetics and Gene Regulation, Department of Gastrointestinal Surgery, Sun YatSen Memorial Hospital, Sun Yat-Sen University, 107 Yan Jiang West Road, Guangzhou 510120, China

2 Department of Oncology, Sun Yat-Sen Memorial Hospital, Sun Yat-Sen University, 107 Yan Jiang West Road, Guangzhou 510120, China Full list of author information is available at the end of the article
} original author(s) and the source, provide a link to the Creative Commons licence, and indicate if changes were made. The images or other third party material in this article are included in the article's Creative Commons licence, unless indicated otherwise in a credit line to the material. If material is not included in the article's Creative Commons licence and your intended use is not permitted by statutory regulation or exceeds the permitted use, you will need to obtain permission directly from the copyright holder. To view a copy of this licence, visit http://creativecommons.org/licenses/by/4.0/. The Creative Commons Public Domain Dedication waiver (http://creativeco mmons.org/publicdomain/zero/1.0/) applies to the data made available in this article, unless otherwise stated in a credit line to the data. 
Conclusions: Positive mSEPT9 is a poor prognostic marker for CRC patients in stage II and III. It is also a powerful complement to TNM staging in predicting postoperative DFS of CRC patients of stage II and III.

Keywords: Colorectal cancer, mSEPT9, Prognosis

\section{Introduction}

CRC was one of the most prevalent tumors with high malignancy in the word, accounting for approximately $8 \%$ of the global cancer burden [1-3]. Surgical excision was the most important treatment for CRC, especially for patients with stage I-III disease [4]. Despite the thoroughness of initial radical resection, approximately $1 / 3$ of patients would face CRC recurrence or metastatic death in stages II and III [5] and thus respond poorly to cancer treatment. TNM staging syetem, edited by American Joint Committee on Cancer was the principal guideline to predict patients prognosis in CRC [6]. But despite patients at the same stage, their outcomes were various, particularly in stage II and stage III [7]. Consequently, detecting high-risk patients with recurrence and metastasis in time and taking further intervention measures to improve the prognosis in stage II and III patients were very necessary. Some studies had suggested that the level of carcinoembryonic antigen before surgery was related to the prognosis of patients [8-10]. However, its sensitivity and specificity were not ideal [11]. Thus, more sensitive indicators should be identified and used as a supplementary part of TNM staging.

The septin 9 gene, located on chromosome 17, is responsible for encoding the septin 9 protein. The gene and its expression products are broadly involved in the growth and metabolic processes of the human body, including division, polarization, apoptosis, and so on [12]. Previous studies confirmed septin 9 gene and



Fig. 1 Flowchart of study design. Peripheral methylated septin 9 gene was detected preoperatively for clinico-pathological and prognosis analysis 
protein in CRC tissues played an anti-cancer effect in the generation and development of tumor. Nevertheless, CpG island hypermethylation of septin 9 promoter could suppress its normal expression, thereby inhibiting its effect [13]. Reports about mSEPT9 had been found in CRC, head and neck cancer, and gastric cancer $[14,15]$. In addition, studies found that a tendency to distant metastasis could be observed in CRC patients with mSEPT9-positive in serum [14, 16, 17]. But the results of mSEPT9 still lacked unified standards in stage II and III.

This research aimed to pick up the prognostic value of mSEPT9 in CRC patients, particularly in TNM stage II and III. We hoped to achieve important prognostic outcomes at a low cost. Furthermore, we made a thorough inquiry into the relation between mSEPT9 and clinico-pathological features in CRC patients.

\section{Methods and materials}

\section{Patients}

To test the value of plasma mSEPT9, 144 of 196 patients with CRC at Sun Yat-sen Memorial Hospital, Guangzhou, China, between March 2017 and January 2020 were enrolled in this study. Following were the inclusion criteria: (I) primary CRC; (II) pathological diagnosis of CRC was determined according to World Health Organization criteria; (III) full clinical information available; (IV) patients received the detection of the methylation of septin 9 gene. The exclusion criteria were described below: (I) patiens did not received surgical treatment; (II) patients did not received septin 9 gene methylation test before surgery; (III) neoadjuvant treatment, including radiation or chemotherapy, was received; The specific inclusion and exclusion were shown in Fig. 1. Chemotherapy regimens for patients were based on NCCN Guidelines [18, 19]. In detail, for the most stage II and all stage III patients, CapeOx and mFOLFOX6 regimen are recommended in priority by the guidelines. As for the T3N0M0 patients in stage II, when there were no risk factors, clinical observation was adopted.

DFS was defined as the time between radical resection of the primary tumor until tumor recurrence or metastasis. Computed Tomography or Magnetic Resonance Imaging was used to monitor the recurrence or metastasis of tumor every 3-6 months. Patients had health checkups by phone every 3-6 months after chemotherapy. Postoperative review strategies were based on NCCN Guidelines [18, 19]. Each patient returned to the hospital every 3 months in the first year and every 6 months in the second and third year for the examination of chest, abdomen and pelvis after surgery or chemotherapy. The median follow-up time was 22.0 months. The final follow-up ended on May 31, 2021.
Table 1 Correlations between serum methylated septin 9 gene and clinico-pathological features of colorectal cancer patients $(n=144)$ (Chi square and Fisher's tests)

\begin{tabular}{|c|c|c|c|}
\hline Parameter & Negative group (\%) & Positive group (\%) & $P$ \\
\hline \multicolumn{4}{|l|}{ Gender } \\
\hline Male & $31(36.0)$ & $55(64.0)$ & \multirow[t]{2}{*}{0.121} \\
\hline Female & $29(50.0)$ & $29(50.0)$ & \\
\hline \multicolumn{4}{|l|}{ Age } \\
\hline$\leqq 60 \mathrm{yr}$ & $26(41.9)$ & $36(58.1)$ & \multirow[t]{2}{*}{0.955} \\
\hline$>60 \mathrm{yr}$ & $34(41.5)$ & $48(58.5)$ & \\
\hline \multicolumn{4}{|l|}{ T stage } \\
\hline T1 & $7(87.5)$ & $1(12.5)$ & \multirow[t]{4}{*}{$<0.001$} \\
\hline $\mathrm{T} 2$ & $13(76.5)$ & $4(23.5)$ & \\
\hline T3 & $18(45.0)$ & $22(55.0)$ & \\
\hline T4 & $22(27.8)$ & $57(72.2)$ & \\
\hline \multicolumn{4}{|l|}{ N stage } \\
\hline NO & $38(46.3)$ & $44(53.7)$ & \multirow[t]{3}{*}{0.116} \\
\hline $\mathrm{N} 1$ & $13(46.4)$ & 15(53.6) & \\
\hline N2 & $9(26.5)$ & $25(73.5)$ & \\
\hline \multicolumn{4}{|c|}{ Distant metastasis (M) } \\
\hline MO & $58(49.6)$ & $59(50.4)$ & \multirow[t]{2}{*}{$<0.001$} \\
\hline M1 & $2(7.4)$ & 25(92.6) & \\
\hline \multicolumn{4}{|l|}{ TNM stage } \\
\hline I & 19(82.6) & $4(17.4)$ & \multirow[t]{4}{*}{$<0.001$} \\
\hline$\|$ & 19(38.8) & $30(61.2)$ & \\
\hline III & $20(44.4)$ & 25(55.6) & \\
\hline IV & $2(7.4)$ & 25(92.6) & \\
\hline \multicolumn{4}{|l|}{ Vascular invasion } \\
\hline Absent & $51(47.7)$ & $56(52.3)$ & \multirow[t]{2}{*}{0.020} \\
\hline Present & $9(24.3)$ & $28(75.7)$ & \\
\hline \multicolumn{4}{|l|}{ Histologic grade } \\
\hline Low level & $1(7.1)$ & 13(92.9) & \multirow[t]{3}{*}{0.006} \\
\hline Medium level & $57(44.9)$ & $70(55.1)$ & \\
\hline High level & $2(66.7)$ & $1(33.3)$ & \\
\hline \multicolumn{4}{|l|}{ Location } \\
\hline Right Colon & 10(30.3) & 23(69.7) & \multirow[t]{3}{*}{0.064} \\
\hline LeftColon & $16(34.8)$ & $30(65.2)$ & \\
\hline Rectum & $34(52.3)$ & $31(47.7)$ & \\
\hline \multicolumn{4}{|l|}{ Microsatellite } \\
\hline $\mathrm{pMMR}$ & $59(45.0)$ & $72(55.0)$ & \multirow[t]{2}{*}{0.008} \\
\hline $\mathrm{dMMR}$ & $1(7.7)$ & $12(92.3)$ & \\
\hline
\end{tabular}

pMMR: proficient mismatch repair; dMMR: deficient mismatch repair

\section{Methylated septin 9 gene detection}

The detection process of mSEPT9 was carried out in strict accordance with the instructions of the EPI Procolon 2.0 CE Kit (provided by Beijing Borcheng Technology Co., Ltd.), and the operation steps were as follows: (1) DNA extraction; (2) Sulfite transformation; (3) Bis DNA binding; (4) Bis DNA purification; (5) PCR of DNA samples using an ABI 7500 fastdx PCR instrument; And (6) 

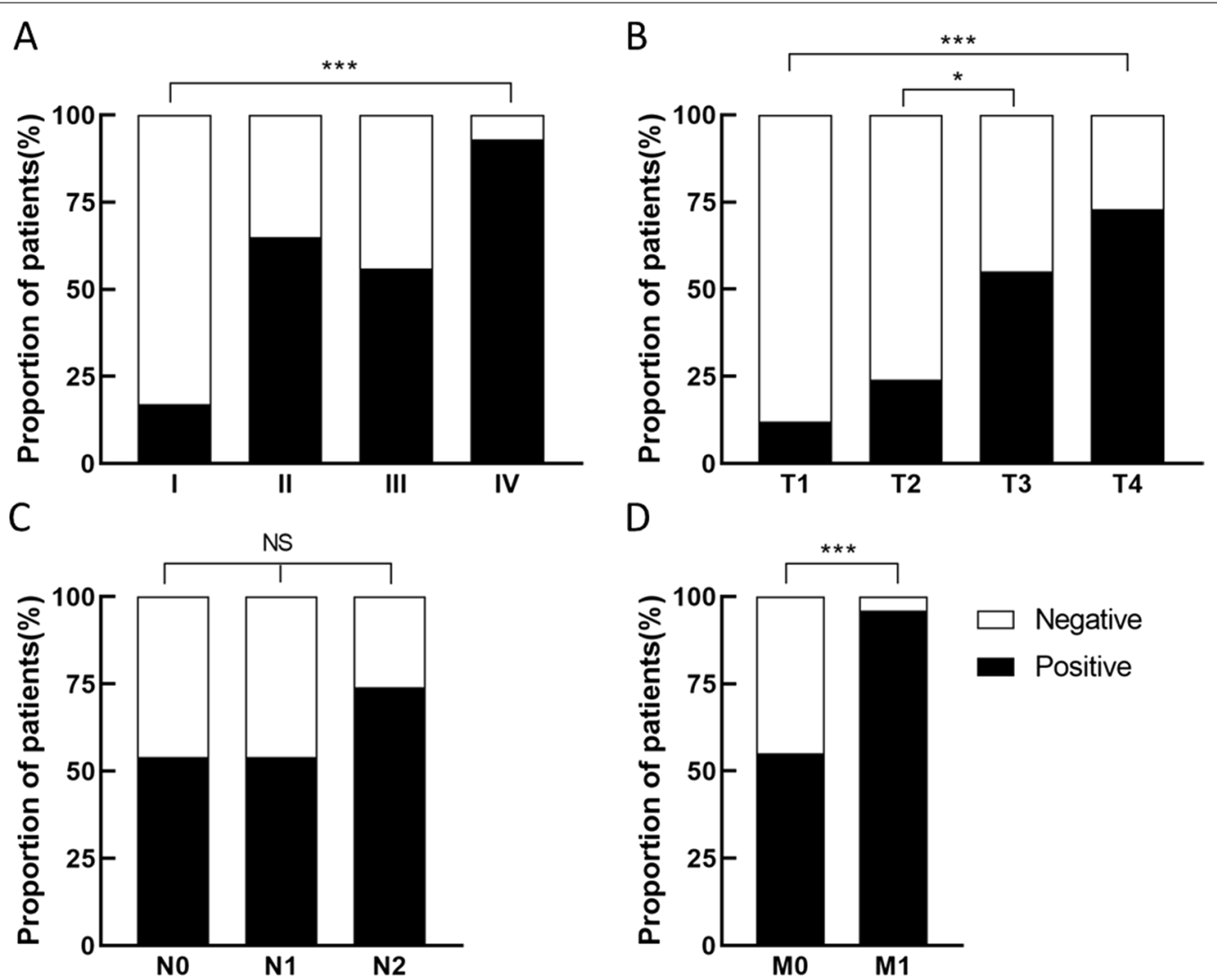

Fig. 2 The proportion of septin 9 gene methylation positive and negative patients under different states. a TNM stage; b T stage; $\mathbf{c} N$ stage; $\mathbf{d} M$ stage. ${ }^{*} P<0.05 ;{ }^{* * *} P<0.001$; NS: no signification

using of the interpretation standard which was carried out according to the instructions of the kit. The human housekeeping gene $\beta$-actin was selected as the internal reference for PCR. PCR was performed three times. If the Ct was lower than the threshold value (41.0) two times, it was judged as positive; otherwise, it was negative.

\section{Immunohistochemistry}

Septin 9 protein was detected in tumor tissues by IHC in 40 of 94 CRC samples in stage II and III. 3 fields $(\times 100, \times 400)$ were randomly selected, and the staining results were determined according to the staining intensity of positive cells and the proportion of positive cells in the tissue. Results semi-quantitative accumulation method was used to determine the specific scoring criteria: (1) Dyeing degree: four different visual chromaticity were rated as 0 point, 1 point, 2 point and 3 point respectively for non-staining, light yellow, brown-yellow and tan. (2) Number of positive cells: $0-5 \%$ cells was 0 point, $6-25 \%$ was 1 point, $25-50 \%$ was 2 point, $>50 \%$ was 3 point. The best cutoff value of the score was decided using the receiver operation characteristic (ROC) curve (Fig. 5a). When the two items were added together, a total score $<3$ was regarded as low expression, while a total score $>=3$ was regarded as high expression.

\section{Statistical analysis}

SPSS 25.0, GraphPad Prism 8, and R 3.6.1 were applied to statistical analyses and graphics. Chi-square tests and Fisher's exact tests were devoted to analyzing the connection between MSEPT9 and other clinico-pathological elements. K-M log-rank test and univariate analysis were used to investigate the relationship between mSEPT9 and DFS, and the variables with a $P<0.05$ were adopted into the multivariate Cox regression 
Table 2 Univariate and multivariate analysis of disease free survival in CRC patients with stage II-III

\begin{tabular}{llll}
\hline Parameter & $\begin{array}{l}\text { Univariate } \\
\text { analysis, } H R(95 \% \\
\mathrm{Cl})\end{array}$ & $P$ & $\begin{array}{l}\text { Mutivariate } \\
\text { analysis, } H R \\
(95 \% \mathrm{Cl})\end{array}$ \\
\end{tabular}

\begin{tabular}{|c|c|c|c|c|}
\hline \multicolumn{5}{|l|}{ Gender } \\
\hline Male & 1 (Referent) & 0.384 & - & - \\
\hline Femal & $\begin{array}{l}0.728(0.357- \\
1.488)\end{array}$ & - & - & - \\
\hline \multicolumn{5}{|l|}{ Age } \\
\hline$\leqq 60 \mathrm{yr}$ & 1 (Referent) & 0.929 & - & - \\
\hline$>60 \mathrm{yr}$ & $\begin{array}{l}0.970(0.499- \\
1.887)\end{array}$ & - & - & - \\
\hline \multicolumn{5}{|l|}{ Tstage } \\
\hline $\mathrm{T} 2-3$ & 1 (Referent) & 0.007 & - & - \\
\hline T4 & $\begin{array}{l}3.346(1.388- \\
8.065)\end{array}$ & - & - & - \\
\hline \multicolumn{5}{|l|}{ N stage } \\
\hline No & 1 (Referent) & $<0.001$ & - & - \\
\hline N1 & $\begin{array}{l}1.312(0.508- \\
3.384)\end{array}$ & - & - & - \\
\hline N2 & $\begin{array}{l}5.290(2.464- \\
11.355)\end{array}$ & - & - & - \\
\hline \multicolumn{5}{|l|}{ TNM stage } \\
\hline$\|$ & 1 (Referent) & 0.005 & 1 (Referent) & 0.003 \\
\hline III & $\begin{array}{l}2.789(1.365- \\
5.700)\end{array}$ & - & $\begin{array}{l}3.010(1.470- \\
6.163)\end{array}$ & \\
\hline \multicolumn{5}{|c|}{ Vascular invasion } \\
\hline Absent & 1 (Referent) & 0.085 & - & - \\
\hline Present & $\begin{array}{l}2.006(1.015- \\
3.964)\end{array}$ & - & - & - \\
\hline \multicolumn{5}{|l|}{ Location } \\
\hline Right Colon & 1 (Referent) & 0.090 & - & - \\
\hline Left Colon & $\begin{array}{l}0.345(0.128- \\
0.933)\end{array}$ & & & \\
\hline Rectum & $\begin{array}{l}0.858(0.405- \\
1.817)\end{array}$ & - & - & - \\
\hline \multicolumn{5}{|l|}{ Microsatellite } \\
\hline pMMR & 1 (Referent) & 0.118 & - & - \\
\hline $\mathrm{dMMR}$ & $\begin{array}{l}2.129(0.825- \\
5.494)\end{array}$ & - & - & - \\
\hline \multicolumn{5}{|l|}{ mSEPT9 } \\
\hline Negative & 1 (Referent) & 0.020 & 1 (Referent) & 0.009 \\
\hline Positive & $\begin{array}{l}2.509(1.175- \\
5.359)\end{array}$ & - & $\begin{array}{l}2.741(1.281- \\
5.865)\end{array}$ & - \\
\hline
\end{tabular}

pMMR: proficient mismatch repair; dMMR: different mismatchrepair; mSEPT9: methylated septin 9 gene; CRC: colorectal cancer

analysis. The correlation between the expression of septin 9 protein in tumor tissue and cancer progression was evaluated using Spearman rank correlation analysis. Based on the results of multivariate analysis, a nomogram of recurrence or metastasis probability was formed. A $P<0.05$ for 2 -side was considered statistically significant.

\section{Results}

Serum mSEPT9-positive was closely related to the advanced-stage of CRC

Patients' complete baseline features and mSEPT9 groups of negative and positive were shown in Table 1. In the study, vascular invasion $(P=0.020)$, microsatellites $(P<0.001)$, histologic grade $(P=0.006)$, TNM stage $(P<0.001)$, tumor infiltration depth $(P<0.001)$ and distant metastasis $(P<0.001)$ were significantly associated with mSEPT9. No significant connection could be seen in gender, age, tumor location, and lymphatic metastasis with mSEPT9. Notably, we further explored the correlation between the status of MSEPT9 and TNM stage. The rate of mSEPT9+ in IV was significantly higher than that in stage I-III, especially in I (92.6\% vs $17.4 \%, P<0.001$, Fig. 2 a). We also analyzed the association of the rate of positive MSEPT9 with the $\mathrm{T}$ stage (T1-T4), N stage (N0-N2), M stage (M0-M1), alonely. The rate of mSEPT9+ revealed a significant increase from T1 to T4 (Fig. 2b), and mSEPT9+ rate in T4 was higher than that in T1 $(72.2 \%$ vs $12.5 \%$, $P<0.001)$. N stage with a slight change in the rate of mSEPT9+ and did not show connection (Fig. 2c). As shown in Fig. 2d, mSEPT9 had an excellent ability to make a distinction between local and metastatic CRC $(P<0.001)$.

\section{mSEPT9 was an independent risk factor for local recurrence or distant metastasis in stage II and stage III CRC patients after surgery.}

At the follow-up period, 38.3\% (36/94) of patients underwent local recurrence or distant progression, with 12 of stage II and 24 of stage III. The DFS rates were $73.4 \%$ and $61.4 \%$ at 12 and 24 months, respectively. The univariate analysis was revealed in Table 2 . mSEPT9, TNM stage, tumor infiltration depth and lymphatic metastasis were significant with DFS $(P<$ 0.05).

mSEPT9 showed a strong relation with DFS. Stage II and stage III patients with mSEPT9+ had a lower DFS rate than those with mSEPT9- (2-year DFS rates, 52.1\% vs $73.9 \%, P=0.014$, Fig. 4 d). The multivariate analysis informed that mSEPT9 had independent prognostic significance for CRC patients $(H R=2.741, P=0.009)$, as well as TNM stage $(H R=3.010, P=0.006)$ (Table 2).

According to above analysis, mSEPT9 and TNM stage were selected to found the nomogram to appraise the risk of relapse or progression of CRC patients (Fig. 3). Each factor corresponds to a number on the scale axis. By adding each score, clinicians and patients could easily calculate the 1-year and 2-year probabilities of DFS. 


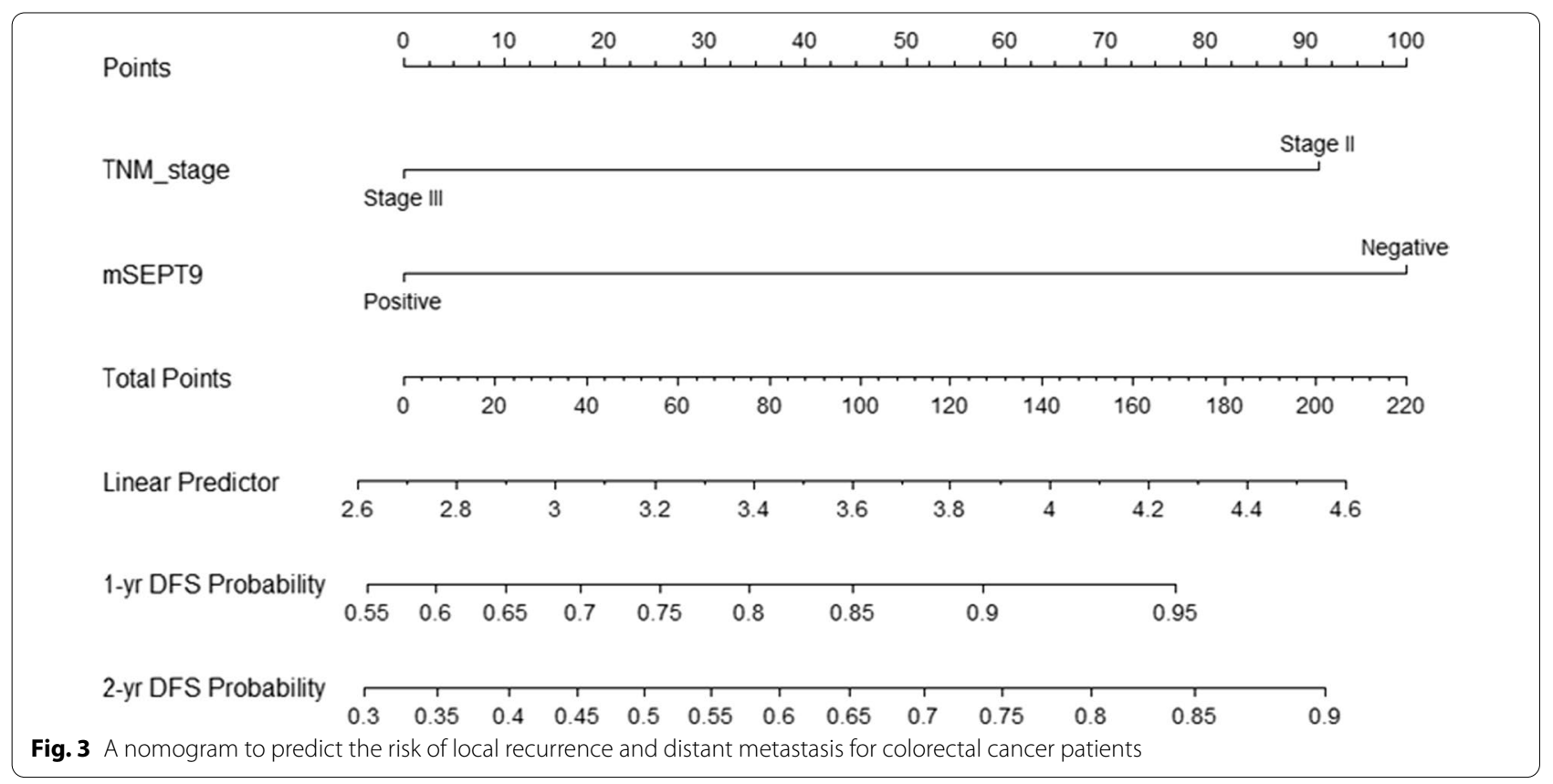

\section{Combining mSEPT9 with TNM stage could better judge the prognosis of CRC patients.}

Based on mSEPT9, the survival was further analyzed. In terms of 2-year DFS, patients with stage II mSEPT9+ performed significantly worse than those with stage II mSEPT9- $(P=0.023$, Fig. 4a), but no statistical difference could be seen between mSEPT9+ and mSEPT9- patients in stage III $(P=0.078$, Fig. $4 \mathrm{~b})$. Besides, although patients with stage II mSEPT9- had better survival than patients in stage III $(P=0.001$, Fig. $4 a)$, patients with mSEPT9+ II had similar survival as patients in stage III $(P=0.132$, Fig. 4a). In the meantime, the survival rate between mSEPT9- in stage III and patients of stage II was close $(P=0.183$, Fig. 4 b). Survival was significantly lower in stage III mSEPT9+ patients than in stage II patients $(P<0.001$, Fig. 4b).

DFS was further stratified by TNM staging and mSEPT9, all results were shown in Fig. 4c. mSEPT9stage II patients had better DFS than mSEPT9patients of stage III $(P=0.012)$. On the survival curve, the stage II mSEPT9+ patients and stage III mSEPT9- patients almost overlapped $(P=0.761)$. As for mSEPT9+ patients in stage II and III, a significant difference could also be seen $(P=0.032)$. Overall, patients had the risk of recurrence or metastasis in the sequence of stage III mSEPT9+, stage III mSEPT9-/ stage II mSEPT9+, and stage II mSEPT9- $(P=0.001)$, from high to low.

\section{Low expression of septin 9 protein in tumor tissues was often related to poor prognosis.}

To investigate the clinical relevance between the septin 9 expression in tumor tissue and cancer progression, septin 9 protein was detected by IHC in 40 CRC patients, including 20 cases in stage II and III, separately (Table 3 ). The cytoplasmic region with brownish-yellow particles was positively expressed (Fig. 5c). Of these tumors, 21 showed high expression, while the remaining 19 showed no or little detectable staining. Patients with low expression of septin 9 in tumor tissue showed significantly poor DFS $(P<0.001$, Fig. $5 b)$. The connection between septin 9 expression and important prognostic risk factors was verified by Spearman correlation analysis, which included recurrence/progression $(R=-0.523, P=0.002)$, mSEPT9 status $(R=-0.451$, $P=0.004), \quad$ and $\quad \mathrm{T} \quad$ stage $(R=-0.375, \quad P=0.017)$ (Table 4).

\section{Discussion}

Although TNM staging is the most important tool to judge the prognosis of colorectal cancer after surgery, some restrictions remained. For instance, patients might have different outcomes regardless of the same stage, especially in stage II and stage III patients [7]. More and more attention has been received in MSEPT9 of CRC, but the results still lacked unified standards in stage II and stage III. In our study, 94 CRC patients in stage II 
A

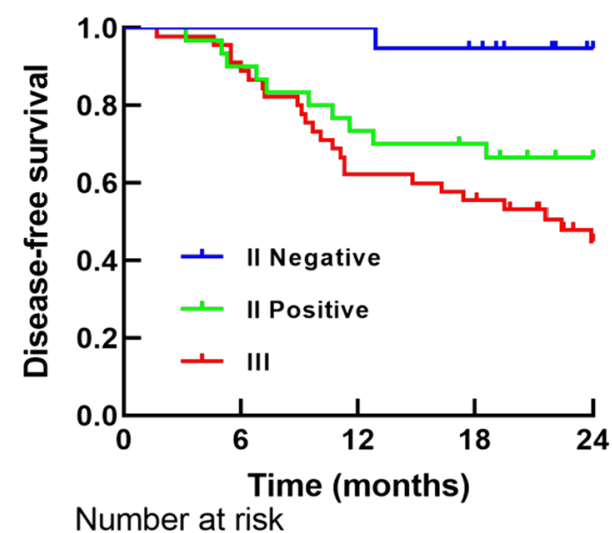

Number at risk

\begin{tabular}{|c|c|c|c|c|c|}
\hline II Negative - & 19 & 19 & 19 & 18 & 9 \\
\hline II Positive - & 30 & 28 & 23 & 21 & 16 \\
\hline III & 45 & 41 & 30 & 26 & 15 \\
\hline
\end{tabular}

C

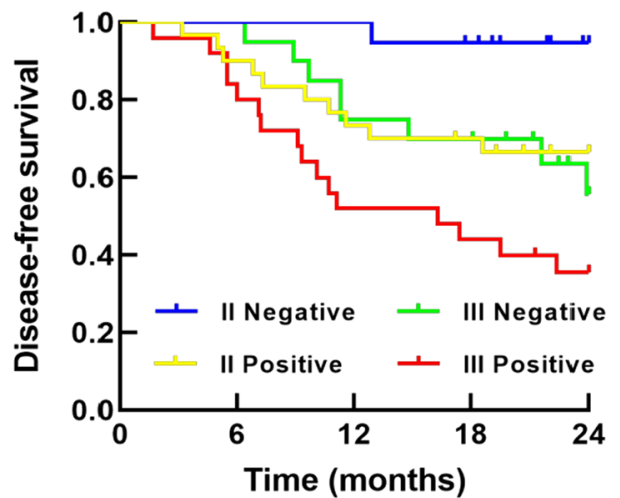

Number at risk

\begin{tabular}{|c|c|c|c|c|}
\hline II Negative - & 19 & 19 & 19 & 18 \\
\hline II Positive - & 30 & 28 & 23 & 21 \\
\hline III Negative - & 20 & 20 & 17 & 15 \\
\hline III Positive - & 25 & 21 & 14 & 12 \\
\hline
\end{tabular}

B

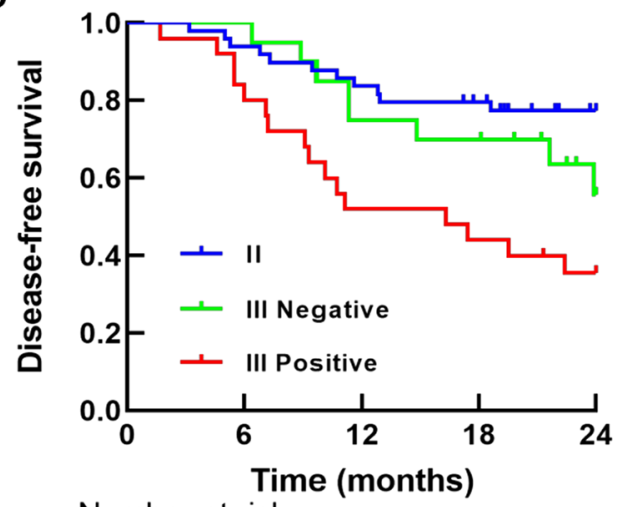

Number at risk

III Negative $=\begin{array}{rrrrr}49 & 47 & 42 & 38 & 25 \\ 20 & 20 & 17 & 15 & 7 \\ 25 & 21 & 14 & 12 & 8\end{array}$



Number at risk

\begin{tabular}{|c|c|c|c|c|c|}
\hline Negative & 39 & 39 & 36 & 31 & 16 \\
\hline Positive & 55 & 48 & 36 & 32 & 24 \\
\hline
\end{tabular}

Fig. 4 Survival curves based on TNM stage and MSEPT9. a-c TNM stage and mSEPT9 were combined for DFS analysis. d DFS was analyzed according to mSEPT9 status. DFS: disease free survival; mSEPT9: methylated septin 9 gene

and III were analyzed by combining mSEPT9. 38.3\% of patients underwent local recurrence or distant metastasis at the 2-year follow-up, consistent with the previous report [23]. Our results confirmed that MSEPT9 was an independent prognosis marker for CRC patients in stage II and III. mSEPT9+ patients showed lower postoperative DFS than mSEPT9- patients. In addition to the above results, we also found that the mSEPT9+ in serum was closely related to the advanced-stage of CRC. Previous studies suggested that septin 9 protein played a tumor suppressive role in CRC [20,21]. However, as the tumor progressed, more and more CpG islands of the septin 9 gene promoter were methylated, affecting its normal gene expression process [13]. As a result, the antitumor effect of the septin 9 protein was limited, leading to a poor prognosis. Our results further confirmed the above conclusion. Through the detection of spetin 9 protein in tumor tissues, we found that when septin 9 protein was low expressed in tumor tissues, its gene methylation level tended to be high in plasma, and low expression of septin 9 protein in tumor tissues was often associated with poor prognosis. Combined with the above results, we had 
Table 3 Clinico-pathological features and septin 9 protein expression in colorectal cancer tissue $(n=40)$

\begin{tabular}{|c|c|}
\hline Parameter & No. of cases (\%) \\
\hline \multicolumn{2}{|l|}{ Age } \\
\hline$\leqq 60 \mathrm{yr}$ & $15(37.5)$ \\
\hline$>60 \mathrm{yr}$ & $25(62.5)$ \\
\hline \multicolumn{2}{|l|}{ Gender } \\
\hline Male & $26(65.0)$ \\
\hline Female & $14(35.0)$ \\
\hline \multicolumn{2}{|l|}{ Location } \\
\hline Right colon & $7(17.5)$ \\
\hline Left colon & $15(37.5)$ \\
\hline Rectum & $18(45.0)$ \\
\hline \multicolumn{2}{|l|}{ T stage } \\
\hline $\mathrm{T} 2$ & $2(5.0)$ \\
\hline T3 & $12(30.0)$ \\
\hline T4 & $26(65.0)$ \\
\hline \multicolumn{2}{|l|}{ N stage } \\
\hline No & $20(50.0)$ \\
\hline N1 & $7(17.5)$ \\
\hline N2 & $13(32.5)$ \\
\hline \multicolumn{2}{|l|}{ TNM stage } \\
\hline$\|$ & $20(50.0)$ \\
\hline III & $20(50.0)$ \\
\hline \multicolumn{2}{|l|}{ Septin 9 of tissue } \\
\hline Strong & $21(52.5)$ \\
\hline Weak & $19(47.5)$ \\
\hline \multicolumn{2}{|l|}{ mSEPT9 } \\
\hline Positive & $23(57.5)$ \\
\hline Negative & $17(42.5)$ \\
\hline \multicolumn{2}{|c|}{ Recurrence/progression } \\
\hline Occurrence & $19(47.5)$ \\
\hline Nothingness & $21(52.5)$ \\
\hline
\end{tabular}

mSEPT9: methylated septin 9 gene

reason to infer that methylated septin 9 gene in serum was an important factor causing the poor prognosis of patients.

And that, the consequences confirmed MSEPT9 was a powerful complement to TNM system. Further survival analysis proved that the survival rate of patients at stage II mSEPT9+ was comparable to that of patients in stage III, and that of patients in stage III mSEPT9- was equivalent to that of patients in stage II. Overlap survival curves for stage II mSEPT9+ and stage III mSEPT9- were observed. So the risk of local recurrence and distant metastasis for
CRC patients after surgery could be stratified into three layers: (1) stage III mSEPT9+ ; (2) stage III mSEPT9- / stage II mSEPT9+; and (3) stage II mSEPT9-. Based on mSEPT9, stage II and III patients could be further classified to provide a basis for individualized adjuvant therapy. Previous studies only simply found that the status of mSEPT9 before surgery was associated with survival of CRC patients [22, 23], lacked in-depth understanding of its specific role. We stratified stage II and III patients in detail using mSEPT9 and clearly demonstrated the role of mSEPT9 in survival outcomes for the first time. Approximately $30 \%$ to $50 \%$ of patients with stage III CRC were at risk for recurrence or metastasis despite thorough excision [24]. And for stage II patients, the 2-year DFS rate was approximately $60 \%$ to $80 \%$ [25]. Chemotherapy could increase the survival rate of CRC patients [26-28]. Finding high-risk patients as early as possible and giving them individualized intervention could greatly improve the survival rate of patients [29].

Our study also revealed some interesting associations between $\mathrm{mSEPT} 9$ and clinicopathological factors. In our research, mSEPT9 performed well as an adjunct molecular staging parameter. A high rate of mSEPT9+ was connected with advanced tumor infiltration and metastasis, but not with lymphatic metastasis. These results add valuable information to the classification of tumors [30,31], and help to guide clinicians to improve examination and treatment plans. In addation, when patients were with deficient mismatch repair, the positive rate of mSEPT9 was at a high level, these results suggested that mismatched repair proteins may play an important role in the methylation of septin 9 gene.

In our research, there are also some limitations. Firstly, in our study, the number of stage II and III patients was relatively small, and the conclusion of further study should be supported by more data. Secondly, due to the short follow-up time, the long-term survival of patients could not be further explored. Finally, our conclusions are not further verified by external data. In the future, multi-center studies on the relationship between septin 9 gene methylation and prognosis in CRC patients should be carried out.

\section{Conclusion}

In conclusion, positive mSEPT9 is a poor prognostic marker for stage II and III CRC patients. It is also a powerful complement to TNM staging in predicting postoperative DFS of CRC patients of stage II and III. 




Table 4 The correlation between the expression of septin 9 protein in tissues and clinico-pathological features $(n=40)$ (Spearman analysis)

\begin{tabular}{lll}
\hline Parameter & $\begin{array}{l}\text { The expression of septin } 9 \\
\text { protein }\end{array}$ \\
\cline { 2 - 3 } & Spearman correlation & $\boldsymbol{P}$ value \\
\hline T stage & -0.375 & $P=0.017$ \\
N stage & -0.258 & $P=0.108$ \\
Vascular invasion & -0.173 & $P=0.286$ \\
mSEPT9 status & -0.451 & $P=0.004$ \\
Recurrence/progression & -0.479 & $P=0.002$
\end{tabular}

mSEPT9: methylated septin 9 gene

\section{Abbreviations}

CRC: Colorectal cancer; Cl: Confidence interval; HR: Hazard ratio; mSEPT9: Methylated septin 9 gene; Ct: Cycle number of the peak reaction; IHC: Immunohistochemical; DFS: Disease-free survival; mSEPT9+: mSEPT9 positive; mSEPT9-: mSEPT9 negative; ROC: Receiver operation characteristic; AUC: Area under the ROC curve; pMMR: Proficient mismatch repair; dMMR: Deficient mismatch repair.

\section{Acknowledgements}

We are grateful to the doctors and nurses working at Sun Yat-sen Memorial Hospital, Sun Yat-sen University for their assistance with this study.

\section{Authors' contributions}

ZZC and XGL: designed the study. MLH: collated the data, analyzed the data, and wrote the manuscript. JHH and WL: participated in the data analysis. $\mathrm{LL}$ and HYX: contributed to drafting the manuscript. YJZ and QSL participated in the immunohistochemistry assays. All authors read and approved the final submitted manuscript. 


\section{Funding}

This work was partly supported by the grant from National Natural Science Foundation of China (81871981), Natural Science Fund of Guangdong Province (2019A1515010646). Medical Scientific Research Foundation of Guangdong Province (A2018319).

\section{Availability of data and materials}

Data supporting the results of this study are available from the corresponding author upon reasonable request.

\section{Declarations}

\section{Ethics approval and consent to participate.}

This study was conducted in accordance with the declaration of Helsinki. Informed consent from the patients was waived by the Institutional Research Ethics Committee of Sun Yat-sen Memorial Hospital because of the retrospective nature of this study, and the study was approved by the Institutional Research Ethics Committee of Sun Yat-sen Memorial Hospital, Sun Yat-sen University (2021-340).

\section{Consent for publication}

Not applicable.

\section{Competing interests}

All authors declare no conflicts of interest.

\section{Author details}

${ }^{1}$ Guangdong Provincial Key Laboratory of Malignant Tumor Epigenetics and Gene Regulation, Department of Gastrointestinal Surgery, Sun YatSen Memorial Hospital, Sun Yat-Sen University, 107 Yan Jiang West Road, Guangzhou 510120, China. ²Department of Oncology, Sun Yat-Sen Memorial Hospital, Sun Yat-Sen University, 107 Yan Jiang West Road, Guangzhou 510120, China. ${ }^{3}$ Guangdong Provincial Key Laboratory of Malignant Tumor Epigenetics and Gene Regulation, Guangdong-Hong Kong Joint Laboratory for RNA Medicine, Sun Yat-Sen Memorial Hospital, Sun Yat-Sen University, Guangzhou 510120, China. ${ }^{4}$ Medical Research Center, Sun Yat-Sen Memorial Hospital, Sun Yat-Sen University, 107 Yan Jiang West Road, Guangzhou 510120, China.

Received: 29 July 2021 Accepted: 16 February 2022

Published online: 28 February 2022

\section{References:}

1. Vatandoost N, Ghambari J, Mojaver M, et al. Early detection of colorectal cancer: from conventional methods to novel biomarkers. J Cancer Res Clin. 2016;142(2):341-51.

2. Siegel RL, Miller KD, Jemal A. Cancer statistics, 2020. CA Cancer J Clin. 2020;70(1):7-30

3. $\mathrm{Ng} \mathrm{SB}, \mathrm{Chua} \mathrm{C}, \mathrm{Ng} \mathrm{M}$, et al. Individualised multiplexed circulating tumour DNA assays for monitoring of tumour presence in patients after colorectal cancer surgery. Sci Rep-UK. 2017;7:40737.

4. Allemani C, Rachet B, Weir HK, Coleman MP, et al. Colorectal cancer survival in the USA and Europe: a CONCORD high-resolution study. BMJ Open. 2013;3(9):e003055.

5. Tsikitis VL, Larson DW, Huebner M, et al. Predictors of recurrence free survival for patients with stage II and III colon cancer. BMC Cancer. 2014;14:336-42.

6. Hortobagyi GN, Edge SB, Giuliano A. New and important changes in the TNM staging system for breast cancer. Am Soc Clin Oncol Educ Book. 2018;38:457-67

7. Liu J, Huang $X$, Yang W, Tang W, et al. Nomogram for predicting overall survival in stage II-III colorectal cancer. Cancer Med. 2020;9(7):2363-71.

8. You W, Yan, Cai Z, et al. Clinical significances of positive postoperative serum CEA and post-preoperative CEA increment in stage II and III colorectal cancer: A multicenter retrospective study. Front Oncol. 2020;10:671-680.

9. Huh JW, Oh BR, Kim HR, et al. Preoperative carcinoembryonic antigen leve as an independent prognostic factor in potentially curative colon cancer. J Surg Oncol. 2010;101(5):396-400.
10. Peng $Y$, Wang $L$, Gu J. Elevated preoperative carcinoembryonic antigen (CEA) and ki67 Is predictor of decreased survival in IIA stage colon cancer. Word J Surg. 2013;37(1):208-13.

11. Young GP, Pedersen SK, Mansfield S, Symonds EL, et al. A cross-sectional study comparing a blood test for methylated BCAT1 and IKZF1 tumorderived DNA with CEA for detection of recurrent colorectal cancer. Cancer Med. 2016;5(10):2763-72.

12. Song L, LiY. SEPT9: a specific circulating biomarker for colorectal cancer. Adv Clin Chem. 2015;72:171-204

13. Tóth K, Galamb O, Spisák S, Tulassay Z, et al. The influence of methylated septin 9 gene on RNA and protein level in colorectal cancer. Pathol Oncol Res. 2011;17(3):503-9.

14. Lee HS, Hwang SM, Kim TS, Park KU, et al. Circulating methylated septin 9 nucleic Acid in the plasma of patients with gastrointestinal cancer in the stomach and colon. Transl Oncol. 2013;6(3):290-6.

15. Schröck A, Leisse A, de Vos L, Dietrich D, et al. Free-circulating methylated DNA in blood for diagnosis, staging, prognosis, and monitoring of head and neck squamous cell carcinoma patients: an observational prospective cohort study. Clin Chem. 2017;63(7):1288-96.

16. LiY, LiY, Liu Y, et al. PAX6, a Novel target of microRNA-7, promotes cellular proliferation and invasion in human colorectal cancer cells. Dig Dis Sci. 2014;59(3):598-606.

17. Freitas M, Ferreira F, Carvalho S, Jerónimo CA, et al. A novel DNA methylation panel accurately detects colorectal cancer independently of molecular pathway. J Transl Med. 2018;16(1):45.

18. Clinical Practice Guidelines in Oncology: rectal cancer (version 1, 2021). National Comprehensive Cancer Network. 2020, 12/22.

19. Clinical Practice Guidelines in Oncology: colon cancer (version 2, 2021). National Comprehensive Cancer Network. 2021, 1/21.

20. Golan M, Mabjeesh NJ. Imaging of hypoxia-inducible factor $1 \mathrm{a}$ and septin 9 interaction by bimolecular fluorescence complementation in live cancer cells. Oncotarget. 2017;8(19):31830-41.

21. Verdier-Pinard $P$, Salaun D, Bouguenina $H$, Badache, et al. Septin 9 i2 is downregulated in tumors, impairs cancer cell migration and alters subnuclear actin filaments. Sci Rep. 2017;7:44976.

22. Yang $X, X u Z$ Z, Chen $X$, Yan YL, et al. Clinical value of preoperative methylated septin 9 in Chinese colorectal cancer patients. World J Gastroenterol. 2019;25(17):2099-109.

23. Sun J, Xu J, Sun C, Zhang S, et al. Screening and prognostic value of methylated septin9 and its association with clinicopathological and molecular characteristics in colorectal cancer. Front Mol Biosci. 2021;8:568818.

24. Shi Q, Andre T, Grothey A, Sargent DJ, et al. Comparison of outcomes after fluorouracil-based adjuvant therapy for stages II and III colon cancer between 1978 to 1995 and 1996 to 2007: evidence of stage migration from the ACCENT database. J Clin Oncol. 2013;31(29):3656-63.

25. Brenner H, Kloor M, Pox CP. Colorectal cancer. Lancet. 2014;383(9927):1490-502.

26. Costas-Chavarri A, Nandakumar G, Temin S, Shah MA, et al. Treatment of patients with early-stage colorectal cancer: ASCO resource-stratified guideline. J Glob Oncol. 2019;5:1-19.

27. Teufel A, Gerken M, Fürst A, Klinkhammer-Schalke M, et al. Benefit of adjuvant chemotherapy in high-risk colon cancer: A 17-year population-based analysis of 6131 patients with Union for International Cancer Control stage II T4N0M0 colon cancer. Eur J Cancer. 2020;137:148-60.

28. Collienne M, Arnold D. The optimal duration of adjuvant chemotherapy in colon cancer. Cancers (Basel). 2020;12(9):2509-21.

29. Greene FL, Stewart AK, Norton HJ, et al. A new TNM staging strategy for node positive (stage III) colon cancer: an analysis of 50,042 patients. Ann Surg. 2002;236(4):416-21.

30. Song L, Jia J, Yu H, Li Y, et al. The performance of the mSEPT9 assay is influenced by algorithm, cancer stage and age, but not sex and cancer location. J Cancer Res Clin Oncol. 2017;143(6):1093-101.

31. Sun J, Fei F, Zhang M, Zhang S, et al. The role of mSEPT9 in screening, diagnosis, and recurrence monitoring of colorectal cancer. BMC Cancer. 2019;19(1):450.

\section{Publisher's Note}

Springer Nature remains neutral with regard to jurisdictional claims in published maps and institutional affiliations. 